\title{
Research on "nature" of Chinese Traditional Cultural Thought and Environmental Art design
}

\author{
${ }^{1}$ North China University of Technology, Beijing, China, 100144 \\ ${ }^{2}$ China Academy of Building Research, Beijing, China, 100013
}

Keywords : Nature, Chinese traditional culture, environmental art, design

Abstract: "nature" of Chinese traditional culture thought and environmental art design from different aspects of the environment influences the architecture, landscape and interior construction, but collectively embodies the basic natural, whole and harmonious layout ideas, also in line with the Taoist the idea of harmony with nature. "Nature" of the traditional Chinese thinking on architecture, landscape and interior design has a very important significance.

\section{"nature" of Chinese traditional Cultural Thought and Architectural Design}

Chinese building use Taoism in the layout of the "nature" of Chinese traditional cultural thought in order to comply with the law of nature embodied, integration with nature. "Nature" expressed in the layout of China for the construction of buildings and different geographical, climate and natural environment outside the building in which to achieve organic harmoniously realm. As Beijing courtyard layout, Tulou layout, caves on the Loess Plateau, minority dry-column layout bamboo house is with local geography, climate and natural environment outside the building in which coordination, reflecting Imitation of Nature Ecological Concept building layout. China Building on the natural environment resources fully utilized, so that the layout of the building in harmony with nature and environment dependent. Hongcun buildings is a typical case of the layout of the building to create a harmonious environment with nature: the introduction of natural water sources in the village, the water passes through the village and flows into the construction of the indoor and outdoor natural, residential streets Bangshui made to the stone paving, water systems and building layout complement each other, like a Chinese landscape painting environment. Chinese people on the "nature" of yearning and create reflected in the layout of the building to create among the emotional sustenance of nature is expressed in the layout of the building passed into. People, geography, building layout and form a "nature" of the organism. "Yard" Taoism building layout is created by the architectural layout of the law. "Yard" means building layout near the mountains and waters and create. Hill is the skeleton of the earth, but also the people's access to natural resources treasure trove of life; water is the source of all angry, "water person, place blood," "primitive things also." Without water, things can not exist, the landscape of human existence the necessary conditions, and be able to resist the invasion of mountain building is set against the cold, and people have "reflects environment Everyday, by water draft" argument, also reflects the importance of the human landscape. Taoist architectural layout view "yin yang, thought and gas." Mountains and water around also illustrate the important role of mountain water in the natural environment of the architectural layout of harmony. Building and mountains in the form of build are: rolling hills surrounded by the hills surrounding the building on a flat plane Piedmont Construction, facing south, and in view of the nature of the looming buildings, rather than the existence of unexpected, so building and merging naturally, also part of nature; and there is a group for the building and construction according to the mountain, the mountain building groups covering the trend, building and create a Chongqing fall into this category, building stairs, magnificent, In this kind of architecture to create a community building to create a majority. Taoism "yard" layout of the building reflects the people's respect for nature and full compliance with the laws of nature would naturally for the people, highlighting the Taoist "nature" of thought.

Chinese building layout to Taoism, "nature" as the basis contains different geographical and cultural characteristics and carries profound historical precipitation, building layout in different geographical reveals the impact of cultural and natural charm in a natural environment . 


\section{"nature" of Chinese traditional Cultural Thought and landscape design}

Taoism basis and origin of "nature" Chinese traditional Cultural Thought, which is the highest state of development. Layout and create inextricably linked ideological "nature" of the garden. Lao Tzu's book, "I", saying: "Act, the law of the heavens, France Road, Imitation of Nature." Lao Zi and ideas flourish, emphasis on natural root and the inaction of the proposed ideas. Taoist respect for nature, inaction, back to nature, indifferent plain and other "nature" views on creating a garden layout are obvious.

"Nature" in a flexible curve expression of nature, so Taoism in Chinese traditional garden layout with a natural, flexible US-based, multi-use soft curves shall make gardens become a part of nature, and nature blending with students. Taoism layout flexible, changeable, and very few use axis or symmetrical layout, designed to trace disappeared people among nature. Garden meandering gallery and innumerable twists and turns of the bridge and the water, integrated nature, reflecting the Chinese garden "nature" back to nature. Gardens building and embankment combined depending on the terrain and built, scatter arrangement, natural water features and building construction, eclectic. The Water Gardens has been able to mimic a variety of water scenes of nature, and stone, earth, mountain landscape combine to create a basic framework of overlapping mountains and water, constituting just like heaven garden landscape. Create a garden on the relationship between landscape Da Qing Dynasty re-light the "painting trap" mentioned: "The mountains of water through their trails, waterways Hedley its Yamagata," the "nature" of the garden layout. Song zhangzeduan of "Jinming Chi Outright map" vividly recreates the grand dragon boat paddle, from painting to the pool can also understand the natural scenery along the willow brush shore, green shop dike. Four Gardens Park and Closed shadow, shadow natural garden environment, fresh and elegant, although the layout of the garden small but excellent Mariko:. "Clip around water, drain Shu Kong, winding down, make for the mountain ring Liu village surrounded by ten thousand, Holland thousand hectares. clear water and more fish, fishing Sao contacts without a break. "shadow Lake Park in the island, the island has a pool, making the park, outside garden water features seamless. Closed in the garden to create a landscape-oriented layout of the whole park natural landscape to create the meantime, the landscape turns, changes in nature, such as natural, density has caused, according to landscape painting landscape management into the room.

Chinese garden is designed back to nature, "nature" to create a garden layout Taoism. Garden buildings, banks, rockeries, water features and other plants to create a natural, flexible layout, varied, eclectic, just like heaven constitute the "nature" garden landscape.

\section{"nature" of Chinese traditional Cultural Thought and interior design}

"Nature" in the interior layout to reduce traces of man-made and natural simplicity, back to nature, simple and pure nature to restore the natural interior layout, interior styling to create a simple and easy way to make people feel a combination of the "Road" realm. Unified integration architecture and nature aspects of the designer Aalto of Finland with his masterpiece, Villa Maria to explain this concept, as a passion for nature and love the designer in his work and ultimately, natural elements, maximize the use of terrain to blend with the natural scenery, in pursuit of a simple and natural style, so vividly before the beauty of nature. In its design of the villa by the architectural space and nature were convergence, creating a continuous extension of the expansion of space changes, so that people can share their feeling with nature. His design philosophy is to blend with nature, the specific approach is to address first election in a scenic hilltop, surrounded by pine covered, building it around among pine trees in the hills turn, through the windows of various intertwined branches, while in the interior is the use of various wood elements, outdoor and indoor neat messy branches furniture casual furnishings, making the integration of indoor and outdoor embraced, looking at everything is so harmonious, like outdoor trees extending chamber . This approach is not simply renovated interior decoration, but rather an organic fusion of indoor outside close to nature under this theme. It is colliding with the rebirth of a variety of natural elements. The 
building built in this lush pine among not simply designed to look good, even fundamentally not for beauty, curved profile buildings around a cozy environment and estates as well as use of the pool of irregular curves, all reflect this building The central idea of the design - it is a natural design around, is to allow people to live where the greatest degree of contact with nature. L-shaped floor plan, with a sauna, swimming pool encircled into a rectangle, this design is to find a balance in the beauty and heating, and gave people a sense of security. While semi-open courtyard in turn living environment combined with the beauty of nature together, reflecting the designer carefully place, considering the closeness with nature and also not forget privacy issues. In the interior design, the door is the restaurant, around the living room and bedroom are on the road leading to the living room to the ladder instead of the door. What has been liberated space. The living room is also designed with ulterior motives, only depending on the surface material will be divided into two parts, a combination of leisure and parlor. In addition to the main entrance, the other side of the indoor gardens associated with internal and external communication, circulation each other indoor and outdoor space, merging, interrelated set off. On the interior design style, bold lines with a variety of elements, there is a straight line curve wave as well as common, mostly wooden decorative materials, all reflect the designer's love for nature, for the public to show the beauty of nature. Indoor layout will view natural outdoor cleverly "borrowed" to the interior, but also "nature" of the hair cut. However, the interior by natural scenery outside, the external nature of the scenery there are certain requirements - Good beautiful natural external conditions. Make full use of the natural environment, the natural environment, wind, water, rocks, flowers and other woven into the room, beautiful natural scenery to be an interior elegant interior layout happen by accident; or open the room window and saw a picture of each landscape different natural scenery, the gorgeous scenery beautiful, refreshing; the building's exterior by a transparent glass, beautiful nature greets the King, like being in the middle of nature.

\section{Conclusion}

"Nature" of the layout concept in environmental design phase defined geographical distinguish Deduction and interpretation, as reflected in complementary yin and yang, the layout of the totally integrated concept of coordination, the built environment accordingly be reasonable distinction. "Nature" thinking create environmental art design in the Chinese culture is set by law, is the overall wisdom of the East Taoism where the basic concept, the establishment of different oriental layout system.

\section{Acknowledgment}

Scientific Research Foundation project funding of North China University of Technology

\section{References}

[1]Ji Xianlin.Oriental Culture Research[M]. Peking University Press.1994

[2]Jiang Xiaoping. Chinese Traditional Architecture Art[M]. Southwest Normal University Press. 1998

[3]Wu Liangyong. Chinese Architecture and Urban Culture[M]. Kunlun Press. 2009 
International Forum on Energy, Environment Science and Materials (IFEESM 2015) 